\title{
The competitive NMDA antagonist CPP protects substantia nigra neurons from MPTP-induced degeneration in primates
}

\author{
Klaus W. Lange ${ }^{1,2}$, Peter-Andreas Löschmann ${ }^{3, *}$, Emin Sofic ${ }^{1}$, Matthias Burg ${ }^{3}$, Reinhard Horowski ${ }^{3}$, \\ Karl T. Kalveram ${ }^{2}$, Helmut Wachtel ${ }^{3}$, and Peter Riederer ${ }^{1}$ \\ ${ }^{1}$ Department of Clinical Neurochemistry, University of Würzburg, Füchsleinstrasse 15, D-97080 Würzburg, Germany \\ ${ }^{2}$ Laboratory of Psychobiology, Institute of General Psychology, University of Düsseldorf, D-40225 Düsseldorf, Germany \\ ${ }^{3}$ Research Laboratories of Schering AG, D-13353 Berlin, Germany
}

Received February 24, 1993/Accepted August 25, 1993

\begin{abstract}
Summary. Degeneration of nigrostriatal dopaminergic neurons is the primary histopathological feature of Parkinson's disease. The neurotoxin MPTP (1-methyl-4phenyl-1,2,3,6-tetrahydropyridine) induces a neurological syndrome in man and non-human primates very similar to idiopathic Parkinson's disease by selectively destroying dopaminergic nigrostriatal neurons. This gives rise to the hypothesis that Parkinson's disease may be caused by endogenous or environmental toxins. Endogenous excitatory amino acids (EAAs) such as L-glutamate could be involved in neurodegenerative disorders including Parkinson's disease. We report in this study that the competitive NMDA antagonist CPP (3-(( \pm$)$-2-carboxypiperazin-4yl)-propyl-1-phosphonic acid) protects nigral tyrosine hydroxylase $(\mathrm{TH})$ positive neurons from degeneration induced by systemic treatment with MPTP in common marmosets. This indicates that EAAs are involved in the pathophysiological cascade of MPTP-induced neuronal cell death and that EAA antagonists may offer a neuroprotective therapy for Parkinson's disease.
\end{abstract}

Key words: Excitatory amino acids - CPP $-3-(( \pm)-2-$ carboxypiperazin-4-yl)-propyl-1-phosphonic acid NMDA receptor antagonist - Dopamine - MPTP 1-Methyl-4-phenyl-1,2,3,6-tetrahydropyridine - Common marmosets - Substantia nigra degeneration Parkinsonism

\footnotetext{
* Present address: Department of Neurology, University of Tübingen, D-72076 Tübingen, Germany

Correspondence to: K.W. Lange at the above address

Abbreviations: AMPA, $\alpha$-amino-3-hydroxy-5-methyl-4-isoxazolepropionate; CPP, 3-(( \pm -2-2-carboxypiperazin-4-yl)-propyl-1-phosphonic acid; DOPAC, dihydroxyphenylacetic acid; EAA, excitatory amino acid; 5-HIAA, 5-hydroxyindolacetic acid; 5-HT, serotonin; HVA, homovanillic acid; MAO-B, monoamine oxidase type B; MK-801, dizocilpine; $\mathrm{MPP}^{+}$, 1-Methyl-4-phenylpyridinium ion; MPTP, 1-Methyl-4-phenyl-1,2,3,6-tetrahydropyridine; NA, noradrenaline; NMDA, N-methyl-D-aspartate; TH, tyrosine hydroxylase; QUIS, quisqualate
}

\section{Introduction}

Administration of MPTP to man or non-human primates (Davis et al. 1979; Langston et al. 1983; Burns et al. 1983) including common marmosets (Jenner et al. 1984) induces a selective destruction of dopaminergic nigrostriatal neurons associated with a substantial decrease in dopamine content of the caudate nucleus and putamen. MPTP is converted by monoamine oxidase type B (MAOB) into the dihydropyridinium species $\left(\mathrm{MPDP}^{+}\right)$which is converted non-enzymatically into the neurotoxic 1-methyl-4-phenylpyridinium ion $\left(\mathrm{MPP}^{+}\right.$; Castagnoli et al. 1985). The latter compound is accumulated intraneuronally by the high affinity dopamine uptake carrier and temporarily stored in a releasable pool (Javitch et al. 1985; Schinelli et al. 1988). $\mathrm{MPP}^{+}$is taken up intraneuronally by a mitochondrial carrier and inhibits complex I of the mitochondrial respiratory chain (Nicklas et al. 1985). EAAs such as L-glutamate or L-aspartate are transmitters in the mammalian central nervous system (Fonnum 1984) and have been claimed to be involved in neurodegenerative disorders including Parkinson's disease (Olney 1989). This assumption is based on the observation that L-glutamate itself (Olney 1969) and compounds activating major glutamate receptor subtypes such as N-methyl-D-aspartate (NMDA, kainate, quisqualate (QUIS) or $\alpha$-amino-3-hydroxy-5-methyl-4-isoxazolepropionate (AMPA) have neurotoxic properties and can produce excitotoxic lesions reminiscent of human neurodegenerative disorders. Several lines of evidence indicate the involvement of EAAs such as glutamate in the neuropathological cascade of MPTP/MPP ${ }^{+}$-induced cell death. MPP ${ }^{+}$induces in rats a release of glutamate and aspartate (Carboni et al. 1990) as well as of dopamine and lactate when delivered through a dialysis probe to the brain (Rollema et al. 1988). Furthermore, we have shown that the neurotoxic effects of $\mathrm{MPP}^{+}$injected focally into the substantia nigra of rats are prevented by systemic treatment with non-competitive and competitive antagonists of NMDA receptors such as dizocilpine (MK-801) or CPP, respectively (Turski et al. 1991). Focal 
administration of $\mathrm{MPP}^{+}$to the brain results in high local concentrations which could possibly produce unspecific toxic effects (Harik et al. 1987). The present study was performed in order to test the hypothesis that EAAs are involved in the mediation of MPTP/MPP ${ }^{+}$. induced neurotoxicity following systemic administration of the neurotoxin. Since rats are not sensitive to MPTP, the effect of MPTP alone and in combination with the competitive NMDA-antagonist CPP was tested in common marmosets. At post mortem the monoamine and metabolite content in the putamen was measured and a quantitative histological analysis of TH positive neurons in the substantia nigra pars compacta was performed.

\section{Materials and methods}

Animals and drugs. Fourteen male and 2 female common marmosets (Callithrix jacchus), weighing $280-420 \mathrm{~g}$, aged 5-15 years and housed under standard conditions at a temperature of $27^{\circ}\left( \pm 1^{\circ} \mathrm{C}\right), 50 \%$ relative humidity and a $12 \mathrm{~h}$ light-dark cycle (light on from $6.00-18.00 \mathrm{~h}$ ) were allocated to four age-matched groups.

The following compounds were employed: CPP (3-(( \pm$)-2-$ carboxypiperazin-4-yl)-propyl-1-phosphonic acid, Research Biochemicals, USA), MPTP (1-methyl-4-phenyl-1,2,3,6-tetrahydropyridine hydrochloride; Schering $A G$ ) dissolved in sterile physiological saline. All solutions were prepared immediately before administration and injected in a volume of $1 \mathrm{ml} / \mathrm{kg}$ body weight. All dosages refer to the free base.

Groups of four animals were treated with either vehicle (A, B) or CPP intraperitoneally ( $25 \mathrm{mg} / \mathrm{kg}$ i.p., B, D) $30 \mathrm{~min}$ prior to the subcutaneous administration of MPTP $(6 \mathrm{mg} / \mathrm{kg}$ s.c., $\mathrm{C}, \mathrm{D})$ or vehicle $(\mathrm{A}, \mathrm{B})$ and subsequently with the same dose of CPP (B, D) or vehicle (A, C) at 4-hourly intervals for up to $44 \mathrm{~h}$ (see Table 1). Forty-eight hours after administration of MPTP or vehicle the animals were sacrificed by an overdose of phenobarbital and the brains quickly removed and divided by a coronal section at the level of the hypophysis. From the rostral portion the putamen was dissected on ice and the caudal part was used for subsequent immunohistochemistry. All samples were immediately transferred into isopentane $\left(-80^{\circ} \mathrm{C}\right)$ and stored at $-70^{\circ} \mathrm{C}$ until histological or biochemical analysis. The MPTP dose $(6 \mathrm{mg} / \mathrm{kg} \mathrm{s.c.})$ was calculated on the basis of previous experiments in this monkey species (Löschmann et al. 1989) and represents the maximum single dose tolerated by animals aged over 10 years. The CPP dose and the treatment intervals were deduced from a pilot experiment in C57 black mice (data not shown). All animal experiments were carried out in accordance with the recommendations of the Declaration of Helsinki and the animal welfare guidelines and laws of Germany.

Determination of biogenic amines. Biogenic amines and metabolites were determined using an HPLC method described earlier (Sofic 1986). Frozen tissue samples were weighed and homogenized in 10 volumes of $0.4 \mathrm{~N}$ perchloric acid containing EDTA and $\mathrm{Na}_{2} \mathrm{~S}_{2} \mathrm{O}_{5}$ and centrifuged at $12000 \mathrm{~g}, 4^{\circ} \mathrm{C}$ for $15 \mathrm{~min}$. Analysis of biogenic amines and metabolites was performed in supernatants using high performance liquid chromatography (HPLC) with coulometric detection for determination of noradrenaline and dopamine (ESA system 5700 and ESA coulochem detector, Model $5100 \mathrm{~A}$ ). Separation of amines was performed on a C18 column (Nucleosil 120-5), the mobile phase consisted of $0.05 \mathrm{M}$ sodium phosphate/sodium acetate buffer, $\mathrm{pH} 3.0$, containing sodium dodecylsulphate and acetonitrile in deionized water (Merck, Lichrosolv). Quantification was performed with dihydrobenzylamide as internal standard. Serotonin, 5-hydroxyindol acetic acid, 3,4-dihydroxyphenylacetic acid and homovanillic acid were measured using an HPLC system (Millipore Waters 460) with electrochemical detection on RP-18 Bondapack columns. The mobile phase consisted of a $0.1 \mathrm{M}$ sodium acetate/acetic acid buffer, $\mathrm{pH} 4.5$, with 5\% methanol and 1 mmol EDTA.

Tyrosine hydroxylase (TH) immunohistochemistry. Tyrosine hydroxylase immunohistochemistry was performed in serial $25 \mathrm{~mm}$ coronal sections of frozen brains through the substantia nigra at $-20^{\circ} \mathrm{C}$ using a cryostat (Leitz 1720 digital). Sections were mounted on gelatine-coated slides, allowed to dry for $90 \mathrm{~s}$ and transferred into fixative $(4 \%$ paraformaldehyde, $10 \%$ saturated picric acid, $2 \%$ sucrose in $0.1 \mathrm{M}$ sodiumphosphate buffer, SPB) for $45 \mathrm{~min}$. Following fixation and rinsing ( $5 \mathrm{~min} 0.1 \mathrm{M} \mathrm{SPB}$ twice) peroxidase activity was removed by brief ( $40 \mathrm{~s})$ exposure to hydrogen peroxide $\left(0.1 \% \mathrm{H}_{2} \mathrm{O}_{2}\right.$ in $\left.0.1 \mathrm{M} \mathrm{SPB}\right)$. Slides were rinsed again ( $5 \mathrm{~min} 0.1 \mathrm{M} \mathrm{SPB}$ twice) and incubated for $30 \mathrm{~min}$ with normal goat serum (NGS $10 \%$ in $0.1 \mathrm{M}$ SPB containing $0.3 \%$ Triton-X-100, SIGMA) and exposed overnight to the primary antibody (1:5000 monoclonal mouse anti-tyrosin hydroxylase, INCSTAR, 2\% NGS, $0.3 \%$ Triton-X-100 in $0.1 \mathrm{M} \mathrm{SPB})$ at $5^{\circ} \mathrm{C}$. After rinsing ( $5 \mathrm{~min}$ $0.1 \mathrm{M} \mathrm{SPB}$ twice) slides were incubated for $1 \mathrm{~h}\left(5^{\circ} \mathrm{C}\right)$ with the secondary antibody ( $1: 200$ biotinylated goat anti-mouse IgG, SIGMA, $2 \%$ NGS, $0.3 \%$ Triton-X-100 in $0.1 \mathrm{M}$ SPB), rinsed twice and incubated for $1 \mathrm{~h}$ $\left(5^{\circ} \mathrm{C}\right)$ with $\mathrm{ABC}(1: 200$ avidin-biotin peroxidase, VECTOR, $2 \%$ NGS in $0.1 \mathrm{M} \mathrm{SPB}$ ) and rinsed twice. The reaction product was visualized using diaminobenzidine $(50 \mathrm{mg} / 100 \mathrm{ml}$, SIGMA, $0.015 \%$ hydrogenperoxide in $0.1 \mathrm{M} \mathrm{SPB}$ ) for $30-60 \mathrm{~min}$ and intensified with osmium tetroxide $(0.005 \%$ in dest. water), if necessary. Slides were left to dry and coverslipped with DePeX (SERVA).

Quantitative histology of TH-positive neurons. For morphological analysis brain sections were visually inspected at all rostro-caudal levels extending from planes $\mathrm{A} 6$ to $\mathrm{A} 3$ according to a standard stereotaxic atlas of marmoset brain (Stephan et al. 1980). Unilateral quantification of intact TH-positive neurons was performed under blind conditions by a single observer (M.B.) at the widest aspect of the substantia nigra pars compacta (SNC) at the level A4-A3.5 using a Leitz Aristoplan microscope equipped with a counting grid (Leitz no. 513740) at a magnification of $\times 100$. For every SNC topographical maps of TH-positive cells were constructed graphically and total counts calculated for two planes on one side. Neurons bearing dendrites and regularly shaped somata were accounted to be normal.

Statistical analysis. Statistical differences between groups in monoamine levels and in the sums of the cell counts at two levels of the substantia nigra were calculated by Kruskal-Wallis one-way analysis of variance followed by post-hoc comparisons using the Mann-Whitney U-test.

Table 1. Group characteristics and treatment schedules. The animals were treated with either vehicle (A, B) or CPP intraperitoneally (25 mg/kg i.p., B,D) $30 \mathrm{~min}$ prior to the subcutaneous administration of MPTP $(6 \mathrm{mg} / \mathrm{kg}$ s.c., C,D) or vehicle (A, B) and subsequently with the same dose of CPP (B,D) or vehicle $(\mathrm{A}, \mathrm{C})$ at 4-hourly intervals for up to $44 \mathrm{~h}$. Four hours later the animals were sacrificed by an overdose of phenobarbital

\begin{tabular}{|c|c|c|c|c|c|}
\hline Group $(n=4)$ & $\begin{array}{l}\text { Mean age } \\
\text { (years, SEM) }\end{array}$ & $\begin{array}{l}\text { Vehicle } \\
\text { (MPTP) }\end{array}$ & $\begin{array}{l}\text { MPTP } \\
\text { (6 mg/kg s.c. once) }\end{array}$ & $\begin{array}{l}\text { Vehicle } \\
\text { (CPP) }\end{array}$ & $\begin{array}{l}\text { CPP } \\
(25 \mathrm{mg} / \mathrm{kg} \text { i.p. every } 4 \mathrm{~h})\end{array}$ \\
\hline (A) Vehicle & $9.75(2.06)$ & $x$ & & $x$ & \\
\hline (C) MPTP & $9.25(1.93)$ & & $x$ & $x$ & \\
\hline (D) $\mathrm{MPTP}+\mathrm{CPP}$ & $9.25(2.02)$ & & $x$ & & $x$ \\
\hline
\end{tabular}




\section{Results}

\section{Behavioural observations}

Treatment with MPTP resulted in a brief period of behavioural stimulation lasting two hours, followed by sedation and hypokinesia, whereas CPP induced sedation. The stimulation caused by MPTP was less pronounced in the group of animals treated with both MPTP and CPP. The animals were continuously observed throughout the experiment; no side effects, other than sedation, were observed.

\section{Effects upon tissue levels of biogenic amines}

In comparison to the control group, tissue concentrations of dopamine metabolites dihydroxyphenylacetic acid (DOPAC) and homovanillic acid (HVA) were decreased in the putamen after MPTP treatment (DOPAC $P=0.043$, HVA: $P=0.021$, Kruskal-Wallis one-way analysis of variance followed by the U-test, cf. Fig. 1). Treatment with CPP did not affect levels of DOPAC, HVA and dopamine. The combined treatment with MPTP and CPP resulted in reduced HVA levels $(P=0.043)$. Due to the variability in tissue concentrations no significant effects upon dopamine concentrations were obtained. Noradrenaline, serotonin (5-HT) and 5-hydroxyindolacetic acid (5-HIAA) in the putamen were not affected by the different treatments (cf. Table 2).

\section{Effects upon TH-positive nigral neurons}

Unilateral cell counts of TH-positive neurons were performed under blind conditions at two levels of the substantia nigra pars compacta of each animal. Treatment with MPTP alone induced a $70 \%$ decrease of intact TH-positive neurons $(P=0.043$, Kruskal-Wallis one-way analysis of variance followed by the U-test, cf Fig. 2), whereas neither CPP alone nor CPP in combination with MPTP affected the cell numbers $(P=0.021$, Kruskal-

Fig. 1A-C. Individual levels of dopamine (A), DOPAC (B) and HVA (C) the putamen (open symbols) and the median with the $25-75$ interquartil ranges (bars) for common marmosets treated with vehicle (VEH), MPTP (6 mg/kg s.c.), CPP ( $25 \mathrm{mg} / \mathrm{kg}$ i.p. at 4-hourly intervals for up to $44 \mathrm{~h}$ ) alone or in combination with MPTP (MPTP + CPP). Levels were determined in tissue homogenates and are given in $\mathrm{ng} / \mathrm{mg}$ tissue wet weight. MPTP caused a significant decrease in DOPAC (B $* P=0.043)$ and HVA $(\mathbf{C} * P=0.021)$ tissue content. Combined treatment MPTP and CPP reduced HVA levels $(\mathrm{C} * P=0.043)$
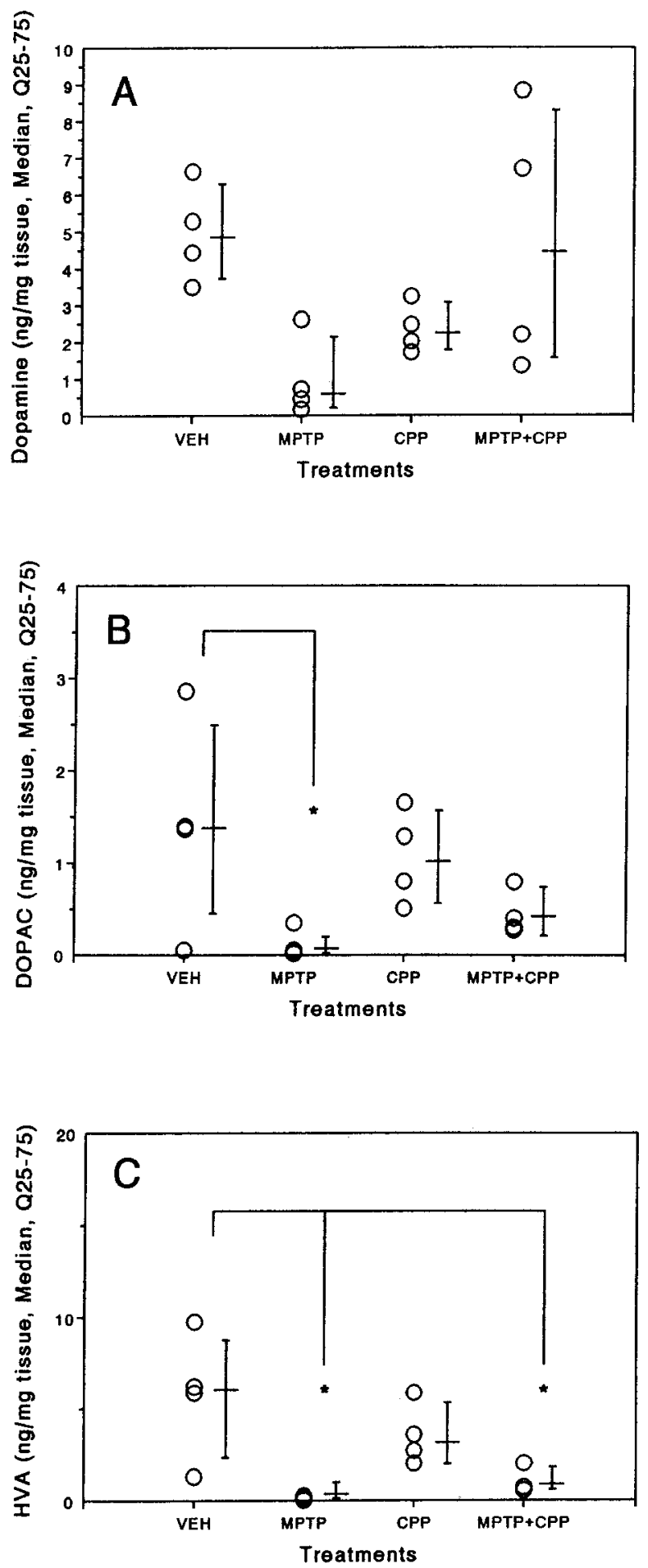

Table 2. Biogenic amines in the putamen. Levels were determined in tissue homogenates (ng/mg tissue wet weight, median, $25-75$ interquartil ranges in parentheses, $n=4$ )

\begin{tabular}{lllll}
\hline Compound & \multicolumn{1}{l}{ Putamen } & & & \\
\cline { 2 - 5 } & Vehicle & CPP & MPTP + CPP & MPTP \\
\hline Noradrenaline & $0.08(0.04-0.13)$ & $0.13(0.07-0.2)$ & $0.07(0.03-0.19)$ & $0.04(0.02-0.33)$ \\
5-HT & $0.25(0.18-0.64)$ & $0.28(0.19-0.32)$ & $0.27(0.11-0.83)$ & $0.79(0.35-1.04)$ \\
5-HIAA & $0.49(0.35-0.76)$ & $0.77(0.36-1.19)$ & $0.56(0.19-1.16)$ & $0.96(0.39-1.51)$ \\
\hline
\end{tabular}




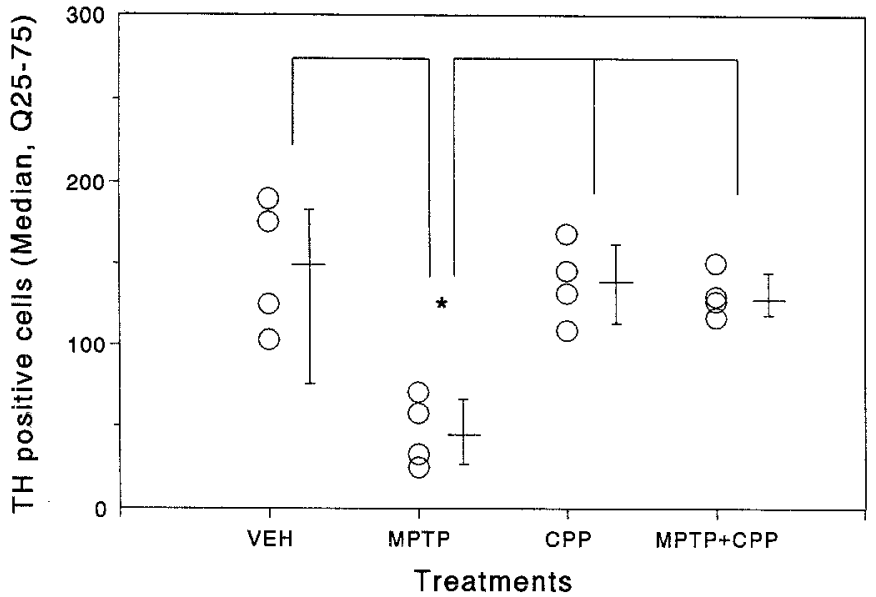

Fig. 2. Intact TH-positive cells. Individual sums of substantia nigra cell counts obtained at two levels (open symbols) and the median with the 25-75 interquartil ranges (bars) for common marmosets treated with vehicle (VEH), MPTP (6 mg/ $\mathrm{kg}$ s.c.), CPP $(25 \mathrm{mg} / \mathrm{kg}$ i.p. at 4-hourly intervals for up to $44 \mathrm{~h}$ ) alone or in combination with MPTP (MPTP + CPP). The number of TH-positive neurons was significantly reduced in the MPTP group $\left({ }^{*} P=0.043 \mathrm{MPTP}\right.$ vs control, $P=0.021$ CPP and CPP +MPTP vs MPTP; Kruskal-Wallis one-way analysis of variance followed by the Mann-Whitney U-test) whereas there were no significant differences between the vehicle-treated group and the CPP or CPP + MPTP groups, respectively

Wallis one-way analysis of variance followed by the U-test vs MPTP, cf Fig. 2). Examples of nigral sections stained for $\mathrm{TH}$ are shown in Fig. 3.

\section{Discussion}

We demonstrate for the first time a protection of nigral neurons from MPTP-induced neurotoxicity by a competitive NMDA antagonist in a primate species. These results are in accordance with findings obtained using the non-competitive NMDA antagonist MK-801 in another primate species (Zuddas et al. 1992). A neuroprotective effect has been observed at the morphological level, i.e. TH-positive (most likely dopaminergic) nigral cell somata are protected.

Acute or subchronic treatment of common marmosets with MPTP results in a drastic decrease of dopamine concentrations in all dopamine-innervated brain areas including the putamen (Rose et al. 1989) causing behavioural sedation and akinesia (Löschmann et al. 1989). The treatment schedule employed with a single high dose of MPTP and repeated injections of CPP has been chosen for two reasons. MPP ${ }^{+}$, formed from MPTP is accumulated by nerve terminals and fibers but not by somata (Herkenham et al. 1991) and is detectable for days in primate brains (Johannessen et al. 1985). In contrast, the half life of CPP in primates is relatively short as deduced from our experiments in MPTP-treated common marmosets (Löschmann et al. 1991). Since the sensitivity of common marmosets to the neurotoxic effects of MPTP seems to be age-related, aged animals $(5-15$ years) were used in the present study. In the vehicle treated group dopamine concentrations in the putamen were in the range of $5 \mathrm{ng} / \mathrm{mg}$ wet weight, whereas $10 \mathrm{ng} / \mathrm{mg}$ have been reported by others (Pérez-Otaño et al. 1991) in juvenile (aged 1-2 years) marmosets. The lower dopamine and metabolite levels in the putamen in our sample could be explained by differences in the dissection technique but we consider an age-related decrease in dopamine content to be the more likely cause. A single dose of MPTP induced an $80 \%$ decrease in dopamine content of the putamen. The levels of the metabolites DOPAC and HVA were significantly reduced and those of the other monoamines analysed were not affected by MPTP-treatment. CPP when administered alone did not affect dopamine levels or other transmitters and metabolites. Combined treatment with MPTP plus CPP caused variable effects on dopamine concentrations (see Fig. 1). However, the combination of MPTP and CPP caused a slight reduction in DOPAC and a significant decrease in HVA. The reduction of metabolite concentrations could be related to the fact the $\mathrm{MPP}^{+}$has MAO blocking properties (Feuerstein et al. 1988). Taken together, these results indicate that CPP provided no protection against MPTP-induced dopamine depletion in the putamen. Subsequent studies employing greater sample sizes may show a significant protection at the neurochemical level.

Non-competitive NMDA antagonists such as MK-801 or phencyclidine as well as the competitive NMDA antagonist D-2-amino-5-phosphopentanoate (D-AP5) cause irreversible pathomorphological changes in the cingulate and retrosplenial cerebral cortex of rats when administered in high doses (Olney et al. 1989). CPP in a dose of $50 \mathrm{mg} / \mathrm{kg}$ i.v. caused a vacuole reaction similar to MK-801 in rats (Olney et al. 1991). Since we used considerably lower doses $(25 \mathrm{mg} / \mathrm{kg})$ and a less effective route of administration (i.p.) it is unlikely that such effects influenced our results.

At the level of nigral dopaminergic cell bodies CPP provides complete protection to $\mathrm{TH}$-positive cells from MPTP-induced degeneration. This effect was evident as late as $48 \mathrm{~h}$ following a single exposure to MPTP. It is very likely that prolonged treatment with $\mathrm{CPP}$ would have extended the period of protection. This speculation needs to be proven in subsequent studies.

Although it is still an unresolved question how $\mathrm{MPTP} / \mathrm{MPP}^{+}$selectively destroys dopaminergic neurons, these results support the notion of a critical involvement of NMDA receptor-mediated events in this process. Due to impairment of mitochondrial respiration resulting in EAA release from glial and neuronal stores. The compromised energy supply, induced by $\mathrm{MPP}^{+}$could result in a partial membrane depolarisation which in turn would remove the voltage-dependent $\mathrm{Mg}^{2+}$ block from NMDA receptor ion channels (Nowak et al. 1984). This would enable EAAs such as glutamate to become neurotoxic through persistent receptor stimulation (Novelli et al. 1988). The compromised energy metabolism and $\mathrm{Ca}^{2+}$ homeostasis are further factors in the increased vulnerability of these cells. The neurotoxicity of MPTP to dopaminergic terminals was not prevented by systemic treatment with CPP since the metabolites DOPAC and, to a greater extent, HVA were reduced in the putamen. At the level of dopaminergic somata, how- 

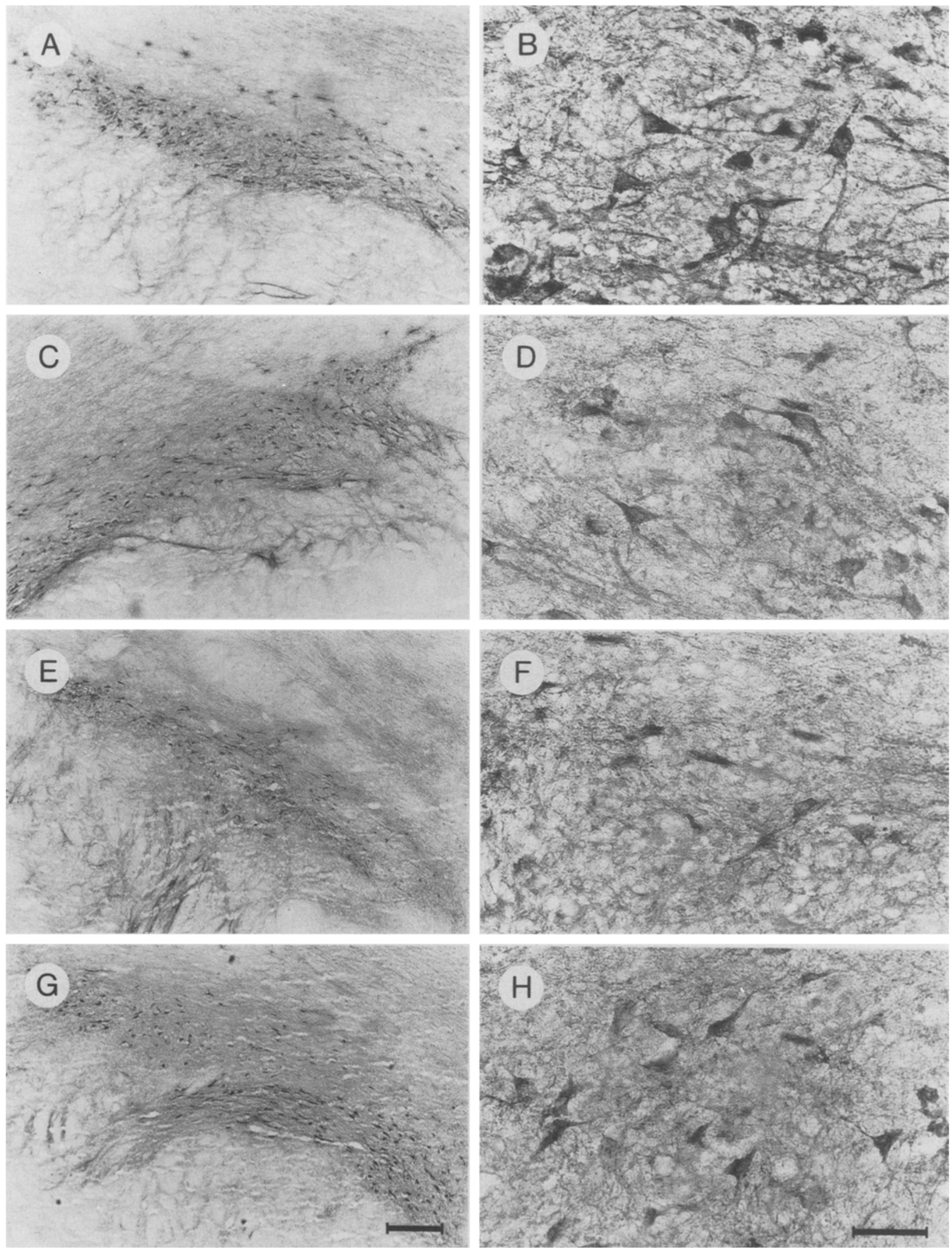

Fig. 3 A-H. Representative nigral sections stained for TH. Given are examples for monkeys treated with vehicle (A, B), CPP (C, D), MPTP (E, F) and MPTP+CPP (G, H). Bars represent $250 \mu \mathrm{m}$ (left panel) and $50 \mu \mathrm{m}$ (right panel) 
ever, blockade of NMDA receptors enables TH-positive neurons to survive. One could speculate that other properties than NMDA antagonism of CPP account for the protection. Theoretically this compound could inhibit the binding of $\mathrm{MPP}^{+}$to neuromelanin in a similar way to chloroquine which protected monkeys against MPTP toxicity (D'Amato et al. 1987). However, since CPP did protect against $\mathrm{MPP}^{+}$injected focally into the substantia nigra of albino rats which is not pigmented (Turski et al. 1991) as well as in common marmosets having a pigmented nigra following systemic treatment with MPTP (this study), this is very unlikely. The discrepancy between our report on the neuroprotective effects of MK-801 and CPP following intranigral injection of $\mathrm{MPP}^{+}$in rats (Turski et al. 1991) and findings showing an absence of protection of MK-801 against striatal dopamine depletion induced by systemic MPTP in mice (Sonsalla et al. 1989) could be explained by this observation. More recently, it was reported that MK-801 failed to protect TH-positive nigral neurons against intranigral $\mathrm{MPP}^{+}$neurotoxicity (Sonsalla et al. 1992). In this study however, MK-801 was administered for only $24 \mathrm{~h}$. This short period of time may not have been adequate to protect nigral neurons. The results of the present study indicate that $\mathrm{TH}$-positive neurons can be protected against MPTP/MPP ${ }^{+}$neurotoxicity by the continuous presence of the NMDA antagonist CPP.

MPTP induces rapid damage of nigral dopamine neurons leading to the development of parkinsonian symptoms in humans and non-human primates within a short period of time, whereas in Parkinson's disease a slowly degenerative process is suggested by the chronic progression of the disease. This difference could indicate that endogenous or environmental compounds, chemically very closely related to MPTP, are probably not a cause for Parkinson's disease. Nevertheless, the striking similarities between the model and the disease suggest at least some common etiopathological features. NMDA receptor-mediated processes are potential factors in the mechanism underlying both Parkinson's disease and MPTP-induced parkinsonism. It has been shown, for example, that the unusual amino acid $\beta$-N-methylamino-L-alanine, probably responsible for the amyotrophic lateral sclerosisparkinsonism-dementia complex of Guam (Spencer et al. 1987), activates glutamate receptors.

NMDA receptor antagonists would seem to offer a neuroprotective treatment for Parkinson's disease, although these results need to be confirmed in clinical trials employing NMDA antagonists. Such an approach could be particularly attractive since we have recently shown that the competitive NMDA antagonist CPP has synergistic effects with L-DOPA in reversing parkinsonian symptoms in MPTP-treated common marmosets (Löschmann et al. 1991). This assumption could be tested directly, since memantine, a compound widely used in Europe as an antiparkinsonian agent, displaces $\left.{ }^{3} \mathrm{H}\right] \mathrm{MK}-801$ in binding studies (Kornhuber et al. 1989) and has non-competitive NMDA antagonistic properties in functional models (Bormann 1989; Lupp et al. 1992). Unfortunately there are no published retrospective or prospective studies on the long-term effects of meman- tine or other amino-adamantanes on the progression of Parkinson's disease. It is therefore still reasonable to hypothesize that NMDA antagonists could improve both the symptomatology and the progression of Parkinson's disease.

Acknowledgement. This study was supported by a grant to K.W.L. and P.R. from the German Federal Ministry of Research and Technology (Grant No. 01 KL 9101).

\section{References}

Bormann J (1989) Memantine is a potent blocker of N-methyl-D-aspartat (NMDA) receptor channels. Eur J Pharmacol 166:591-592

Burns RS, Chiueh CC, Markey SP, Ebert MH, Jacobowitz DM, Kopin IJ (1983) A primate model of parkinsonism; selective destruction of dopaminergic neurons in the pars compacta of the substantia nigra by N-methyl-4-phenyl-1,2,3,6-tetrahydropyridine. Proc Natl Acad Sci USA 80:4546-4550

Carboni S, Melis F, Pani L, Hadliconstantinou M, Rossetti Z (1990) The non-competitive NMDA-receptor antagonist MK-801 prevents the massive release of glutamate and aspartate from rat striatum induced by 1-methyl-4-phenylpyridinium $\left(\mathrm{MPP}^{+}\right)$. Neurosci Let $117: 129-133$

Castagnoli A Jr, Chiba K, Trevor AJ (1985) Potential bioactivation pathways for the neurotoxin 1-methyl-4-phenyl-1,2,3,6-tetrahydropyridine (MPTP). Life Sci 36:225-230

D'Amato RJ, Alexander GM, Schwartzman RJ, Kitt AC, Price DL, Snyder SH (1987) Neuromelanin: a role in MPTP-induced neurotoxicity. Life Sci 40:705-712

Davis GC, Williams AC, Markey SP, Ebert MH, Caine ED, Reichert CM, Kopin IJ (1979) Chronic parkinsonism secondary to intravenous injection of meperidine analogues. Psychiat Res $1: 249-254$

Feuerstein TJ, Hedler L, Jackisch R, Hertting G (1988) An in vitro model of 1-methyl-4-phenyl-pyridinium $\left(\mathrm{MPP}^{+}\right)$toxicity: incubation of rabbit caudate nucleus slices with $\mathrm{MPP}^{+}$followed by biochemical and functional analysis. Br J Pharmacol 95:449-458

Fonnum F (1984) Glutamate: A neurotransmitter in mammalian brain. J Neurochem 42:1-11

Harik SI, Schmdley JW, Iacofano LA, Blue P, Arora PK, Sayre LM (1987) On the mechanism of underlying 1-methyl-4-phenyl1,2,3,6-tetrahydropyridine neurotoxicity: the effects of perinigral infusion of 1-methyl-4-phenyl-1,2,3,6-tetrahydropyridine, its metabolite and their analogs in the rat. J Pharmacol Exp Ther 241:669-676

Herkenham M, Little MD, Bankiewicz K, Yang SC, Markey SP, Johannessen JN (1991) Selective retention of $\mathrm{MPP}^{+}$within the monaminergic system of the primate brain following MPTP administration: an in vivo autoradiographic study. Neuroscience 40:133-158

Javitch A, D'Amato RJ, Strittmatter SM, Snyder SH (1985) Parkinsonism inducing neurotoxin, N-methyl-4-phenyl-1,2,3,6-tetrahydropyridine: uptake of the metabolite $\mathrm{N}$-methyl-4-phenylpyridine by dopamine neurons explains selective toxicity. Proc Natl Acad Sci USA 82:2173-2177

Jenner P, Rupniak NMJ, Rose S, Kelley E, Kilpatrick G, Lees A, Marsden CD (1984) 1-Methyl-4-phenyl-1,2,3,6-tetrahydropyridineinduced parkinsonism in the common marmoset. Neurosci Lett $50: 85-90$

Johannessen JN, Chiueh CC, Burns RS, Markey SP (1985) Differences in metabolism of MPTP in the rodent and primate parallel differences in sensitivity to its neurotoxic effects. Life Sci 36:219

Kornhuber J, Bormann J, Retz W, Hübers M, Riederer P (1989) Memantine displaces $\left[{ }^{3} \mathrm{H}\right] \mathrm{MK}-801$ at therapeutic concentrations in postmortem human frontal cortex. Eur J Pharmacol 166:589-590

Langston JW, Ballard B, Tetrud JW, Irwin I (1983) Chronic parkinsonism in humans due to a product of meperidine-analog synthesis. Science 225:1480-1482 
Löschmann PA, Chong PN, Nomoto M, Tepper PG, Horn AS, Jenner P, Marsden CD (1989) Stereoselective reversal of MPTP-induced parkinsonism in the marmoset after dermal application of $\mathrm{N}-0437$. Eur J Pharmacol 166:373-380

Löschmann PA, Lange KW, Kunow M, Rettig KJ, Jähnig P, Honoré T, Turski L, Wachtel H., Jenner P, Marsden CD (1991) Synergism of the AMPA-antagonist NBQX and the NMDA-antagonist CPP with L-Dopa in models of Parkinson's disease. J Neural Transm [PD Sec] 3:203-213

Lupp A, Lücking CH, Koch R, Jackisch R, Feuerstein TJ (1992) Inhibitory effects of the antiparkinsonian drugs memantine and amantadine on N-methyl-D-aspartate-evoked acetylcholine release in the rabbit caudate nucleus in vitro. $J$ Pharmacol Exp Ther 263:717-724

Nicklas WJ, Vyas I, Heikkila RE (1985) Inhibition of NADH-linked oxidation in brain mitochondria by 1-methyl-4-phenylpyridine, a metabolite of the neurotoxin 1-methyl-4-phenyl-1,2,3,6-tetrahydropyridine. Life Sci 36:2503-2508

Novelli A, Reilly JA, Lysko PG, Henneberry RC (1988) Glutamate becomes neurotoxic via the $\mathrm{N}$-methyl-D-aspartate receptor when intracellular energy levels are reduced. Brain Res 451:205-212

Nowak L, Bregestovski P, Ascher P, Herbet A, Prochiantz A (1984) Magnesium gates glutamate-activated channels in mouse central neurons. Nature 307:462-465

Olney JW (1969) Brain lesions, obesity and other disturbances in mice treated with monosodium glutamate. Science 164:719-721

Olney JW (1989) Excitotoxicity and N-Methyl-D-aspartate receptors. Drug Dev Res 17:299-319

Olney JW, Labruyere J, Price MT (1989) Pathological changes induced in cerebrocortical neurons by phencyclidine and related drugs. Science 244:1360-1362

Olney JW, Labruyere J, Wang G, Wozniak DF, Price MT, Sesma MA (1991) NMDA antagonist neurotoxicity: mechanism and prevention. Science 254:1515-1518

Pérez-Otaño I, Herrero MT, Oset C, De Ceballos ML, Luquin MR, Obeso JA, Del Rio J (1991) Extensive loss of brain dopamine and serotonin induced by chronic administration of MPTP in the marmoset. Brain Res 567:127-132
Rollema H, Kuhr WG, Kranenborg G, DeVries J, Van den Berg C (1988) $\mathrm{MPP}^{+}$induced efflux of dopamine and lactate from rat striatum have similar time courses as shown by in vivo brain dialysis. J Pharmacol Exp Ther 245:858-866

Rose S, Nomoto M, Jenner P, Marsden CD (1989) Transient depletion of nucleus accumbens dopamine content may contribute to initial akinesia induced by MPTP in common marmosets. Biochem Pharmacol 38:3677-3681

Schinelli S, Zuddas A, Kopin IJ, Barker JL, di Prozio U (1988) 1-Methyl-4-phenyl-1,2,3,6-tetrahydropyridine and 1-methyl-4-phenylpyridinium uptake in dissociated cell cultures from embryonic mesencephalon. J Neurochem 50:1900-1907

Sofic E (1986) Determinations of biogenic amines, metabolites, ascorbic acid and glutathion by HPLC-ECD. Doctoral Thesis, Techn Univ Vienna

Sonsalla PK, Nicklas WJ, Heikkila RE (1989) Role for excitatory amino acids in methamphetamine-induced nigrostriatal dopaminergic toxicity. Science 243:398-400

Sonsalla PK, Zeevalk GD, Manzino L, Giovanni A, Nicklas WJ (1992) MK-801 fails to protect against the dopaminergic neuropathology produced by systemic 1-methyl-4-phenyl-1,2,3,6-tetrahydropyridine in mice or intranigral 1-methyl-4-phenylpyridinium in rats. J Neurochem 58:1979-1982

Spencer PS, Nunn PB, Hugon J, Ludolph AC, Ross SM, Richard DN, Robertson C (1987) Guam amyotrophic lateral sclerosis-parkinson dementia linked to a plant excitant neurotoxin. Science 237: $517-522$

Stephan H, Baron G, Schwerdtfeger WK (1980) The brain of the common marmoset. Springer, Berlin Heidelberg New York

Turski L, Bressler K, Rettig KJ, Löschmann PA, Wachtel H (1991) Protection of substantia nigra from $\mathrm{MPP}^{+}$neurotoxicity by N-methyl-D-aspartate antagonists: Nature 349:414-418

Zuddas A, Oberto G, Vaglini F, Fascetti F, Fornai F, Corsini GU (1992) MK-801 prevents 1-methyl-4-phenyl-1,2,3,6-tetrahydropyridine-induced parkinsonism in primates. J Neurochem 59:733-739 